\title{
Vertical profiles of droplet effective radius in shallow convective clouds
}

\author{
S. Zhang ${ }^{1}$, H. Xue ${ }^{1}$, and G. Feingold ${ }^{2}$ \\ ${ }^{1}$ Department of Atmospheric and Oceanic Sciences, School of Physics, Peking University, Beijing, China \\ ${ }^{2}$ NOAA Earth System Research Laboratory, Boulder, Colorado, USA
}

Received: 8 December 2010 - Published in Atmos. Chem. Phys. Discuss.: 21 December 2010

Revised: 23 April 2011 - Accepted: 6 May 2011 - Published: 17 May 2011

\begin{abstract}
Conventional satellite retrievals can only provide information on cloud-top droplet effective radius $\left(r_{\mathrm{e}}\right)$. Given the fact that cloud ensembles in a satellite snapshot have different cloud-top heights, Rosenfeld and Lensky (1998) used the cloud-top height and the corresponding cloud-top $r_{\mathrm{e}}$ from the cloud ensembles in the snapshot to construct a profile of $r_{\mathrm{e}}$ representative of that in the individual clouds. This study investigates the robustness of this approach in shallow convective clouds based on results from large-eddy simulations (LES) for clean (aerosol mixing ratio $N_{\mathrm{a}}=25 \mathrm{mg}^{-1}$ ), intermediate $\left(N_{\mathrm{a}}=100 \mathrm{mg}^{-1}\right)$, and polluted $\left(N_{\mathrm{a}}=2000 \mathrm{mg}^{-1}\right)$ conditions. The cloud-top height and the cloud-top $r_{\mathrm{e}}$ from the modeled cloud ensembles are used to form a constructed $r_{\mathrm{e}}$ profile, which is then compared to the in-cloud $r_{\mathrm{e}}$ profiles. For the polluted and intermediate cases where precipitation is negligible, the constructed $r_{\mathrm{e}}$ profiles represent the in-cloud $r_{\mathrm{e}}$ profiles fairly well with a low bias (about $10 \%$ ). The method used in Rosenfeld and Lensky (1998) is therefore validated for nonprecipitating shallow cumulus clouds. For the clean, drizzling case, the in-cloud $r_{\mathrm{e}}$ can be very large and highly variable, and quantitative profiling based on cloudtop $r_{\mathrm{e}}$ is less useful. The differences in $r_{\mathrm{e}}$ profiles between clean and polluted conditions derived in this manner are however, distinct. This study also investigates the subadiabatic characteristics of the simulated cumulus clouds to reveal the effect of mixing on $r_{\mathrm{e}}$ and its evolution. Results indicate that as polluted and moderately polluted clouds develop into their decaying stage, the subadiabatic fraction $f_{\text {ad }}$ becomes smaller, representing a higher degree of mixing, and $r_{\mathrm{e}}$ becomes smaller $(\sim 10 \%)$ and more variable. However, for the clean case, smaller $f_{\text {ad }}$ corresponds to larger $r_{\mathrm{e}}$ (and larger
\end{abstract}

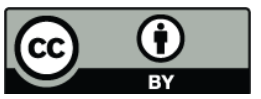

Correspondence to: $\mathrm{H}$. Xue (hxue@pku.edu.cn) $r_{\mathrm{e}}$ variability), reflecting the additional influence of droplet collision-coalescence and sedimentation on $r_{\mathrm{e}}$. Finally, profiles of the vertically inhomogeneous clouds as simulated by the LES and those of the vertically homogeneous clouds are used as input to a radiative transfer model to study the effect of cloud vertical inhomogeneity on shortwave radiative forcing. For clouds that have the same liquid water path, $r_{\mathrm{e}}$ of a vertically homogeneous cloud must be about $76-90 \%$ of the cloud-top $r_{\mathrm{e}}$ of the vertically inhomogeneous cloud in order for the two clouds to have the same shortwave radiative forcing.

\section{Introduction}

Aerosol-cloud interactions are recognized as one of the largest uncertainties in the prediction of climate change. Representation of shallow convection in climate models is a major challenge because the relevant spatiotemporal scales are on the order of tens to hundreds of meters and seconds, i.e., scales much smaller than those that can be resolved by climate models, both now and in the foreseeable future (e.g., Lohmann and Feichter, 2005; Wang and Penner, 2009). Recent studies have shown that the manner in which warm clouds and their interaction with aerosol particles are represented by climate models has a marked effect on climate sensitivity - i.e., the Earth's temperature response to a doubling of $\mathrm{CO}_{2}$.

The underlying processes associated with aerosol effects on clouds are qualitatively well-understood. Higher aerosol concentrations lead to an increase in cloud droplet concentration and a decrease in droplet size, thus an increase in cloud visible albedo for constant liquid water path (LWP) (Twomey, 1974, 1977). Higher aerosol concentration may also increase the amount of low-level cloudiness and cloud

Published by Copernicus Publications on behalf of the European Geosciences Union. 
lifetime through a reduction of drizzle, imposing an additional cooling effect on the global climate system (Albrecht, 1989). However, the cloud lifetime effect and other processes such as the influence of aerosol on entrainment mixing are not well-understood (e.g., Jeffery and Reisner, 2006).

Quantification of aerosol-cloud interaction (ACI) is sometimes expressed as $\mathrm{ACI}=-d \ln r_{\mathrm{e}} / d \ln \tau$ at fixed LWP, where $r_{\mathrm{e}}$ is the cloud droplet effective radius, and $\tau$ is the aerosol optical depth (Feingold et al., 2001; Feingold, 2003). McComiskey and Feingold (2008) found that an error of 0.05 in ACI can lead to large changes in the estimation of the radiative forcing. The fact that many field observations and satellite measurements to date have shown that ACI is highly variable (e.g., Feingold et al., 2003; Breon et al., 2002) suggests that there is large uncertainty in cloud albedo forcing. This is partly because physical mechanisms may vary under different conditions and locations, but ACI is also quite sensitive to the method of remote $r_{\mathrm{e}}$ retrieval (Rosenfeld and Feingold, 2003) and to the aerosol proxy for cloud condensation nuclei (McComiskey et al., 2009). In general, in-situ and ground-based observations of ACI tend to be higher and closer to the theory of droplet activation than those from satellites.

The horizontal and vertical variability of $r_{\mathrm{e}}$ imposes difficulty on $r_{\mathrm{e}}$ retrievals and hence uncertainty in ACI estimation. As shown in many field observations, droplet size not only exhibits horizontal heterogeneity, but also vertical stratification (e.g., Warner, 1955; Brenguier et al., 2000; Miles et al., 2000; Hudson and Yum, 2001; Twohy et al., 2005; Jiang et al., 2008; Lu et al., 2008; Arabas et al., 2009). The vertical stratification of droplet size must be resolved because it is central to both the cloud albedo and the precipitation process (Brenguier et al., 2003; Rosenfeld and Lensky, 1998). Although in situ measurements can resolve vertical profiles of droplet size, they cannot provide regional or global scale data sets for understanding and parameterization of aerosol effects on climate. Robust and widely applicable methods are needed for retrieving profiles of cloud droplet $r_{\mathrm{e}}$. Groundbased remote sensing can retrieve droplet size profiles using millimeter cloud radar, with a constraint of microwavederived LWP and assuming a droplet size distribution model, a fixed spectral breadth, and a constant droplet number concentration (Frisch et al., 1995). Measurements of $r_{\mathrm{e}}$ from satellite radiometers such as the Advanced Very High Resolution Radiometer (AVHRR) and Moderate Resolution Imaging Spectroradiometer (MODIS) tend to be confined to cloud top because a single near infrared (NIR) channel is more sensitive to the layer near cloud top rather than the lower layers (e.g., Nakajima and King, 1990). A recent study has revealed that the retrieval of droplet size can be strongly influenced by the vertical inhomogeneity of droplet size (Nakajima et al., 2010). Retrieving vertical profiles of $r_{\mathrm{e}}$ from satellite radiometers has only become feasible in recent years for lowlevel, nonprecipitating stratiform clouds by assuming linear $r_{\mathrm{e}}$ profiles and with the use of MODIS shorter wavelength measurements that penetrate deeper into the clouds (Chang and Li, 2002; Chen et al., 2008).

Because of the difficulty of deriving $r_{\mathrm{e}}$ profiles from conventional satellite measurements, Rosenfeld and Lensky (1998) and Lensky and Rosenfeld (2003) used the cloud-top height and the corresponding cloud-top $r_{\mathrm{e}}$ from the cloud ensembles in the satellite snapshot to construct a profile of $r_{\mathrm{e}}$ that can be used to represent the $r_{\mathrm{e}}$ profile in the absence of precipitation. In so doing, they assumed that cloud-top properties observed for cloud ensembles in the snapshot (each cloud having different cloud-top height and sampled at a different stage of the vertical growth) are similar to the properties of a single cloud as it grows through various heights (Arakawa and Schubert, 1974). This assumption of time-space exchangeability has been validated by Lensky and Rosenfeld (2006). The cloud-top height vs. cloud-top $r_{\mathrm{e}}$ relationship for the snapshot was compared with the composite $r_{\mathrm{e}}$ profile for individual clouds tracked along their lifecycle, using 3-min satellite images. They confirmed that the composite properties from tracking the cells reproduce the properties in the snapshot. Because entrainment-mixing is significant for convective clouds, and because the top and the sides of convective clouds may experience different degrees of mixing (e.g., Warner, 1955; Blyth et al., 1988; Blyth, 1993; Burnet and Brenguier, 2007; Small and Chuang, 2008; Jiang et al., 2008; Lu et al., 2008), cloud droplet size at cloud top and inside of clouds and clouds at different stages of the lifecycle may deviate from the adiabatic value to different degrees. However, if entrainment mixing is inhomogeneous, then cloud droplet size is likely independent on the degree of mixing (Freud et al., 2008). The assumption that cloudtop $r_{\mathrm{e}}$ acquired by satellites is representative of in-cloud $r_{\mathrm{e}}$ at the same height for shallow convective clouds, as used in Rosenfeld and Lensky (1998), will be tested here.

In global climate model parameterizations, $r_{\mathrm{e}}$ is usually assumed to be vertically fixed or dependent on cloud thickness. Brenguier et al. (2003) pointed out that cloud vertical stratification must be taken into account in climate model parameterizations of cloud radiative properties and can be approximated with an adiabatic model for stratus clouds. It should also be noted that the stratified cloud model has been used to develop procedures for the retrieval of cloud geometrical thickness, liquid water content, and drop number concentration from the measurement of cloud radiances for stratiform clouds (Schüller et al., 2005). How to use this kind of cloud model for parameterization and retrieval in shallow convective clouds remains uncertain because the mixing process can lead to significant changes in cloud microphysical properties (Warner, 1955).

In this paper, we use LES results to investigate $r_{\mathrm{e}}$ vertical profiles in shallow convective clouds. It has been demonstrated that the sensitivity of cloud visible albedo to changes in cloud droplet size distribution is greatest for shallow clouds rather than very thick and water-rich clouds which have large visible albedos (Platnick and Twomey, 1994). The 
simulations in this study are based on the Barbados Oceanographic and Meteorology Experiment (BOMEX), during which steady-state cumulus convection was observed for a period of several days. More details of the simulations can be found in Xue and Feingold (2006). The spatial variability of $r_{\mathrm{e}}$ is investigated to shed light on implications for both satellite retrieval and model parameterization of the aerosol effects (Brenguier et al., 2003). We investigate whether the in-cloud $r_{\mathrm{e}}$ profiles can be constructed using cloud-top $r_{\mathrm{e}}$ and the corresponding cloud-top height from satellite measurements for convective clouds. The in-cloud variability of $r_{\mathrm{e}}$ is compared in each case to the variability due to aerosol effects. The evolution of $r_{\mathrm{e}}$ profiles and the degree to which $r_{\mathrm{e}}$ profiles are affected by mixing are also studied. A planeparallel radiative transfer model is then used to investigate the effect of cloud vertical inhomogeneity on shortwave radiative forcing. The model data and methods are described in Sect. 2. Results and discussions are presented in Sect. 3, and conclusions are summarized in Sect. 4.

\section{Data and method}

Data used in this study are model output from a set of largeeddy simulations of trade cumuli with aerosol mixing ratios of $N_{\mathrm{a}}=25,100$ and $2000 \mathrm{mg}^{-1}$ (mixing ratio units of $\mathrm{mg}^{-1}$ are approximately equal to $\mathrm{cm}^{-3}$ ) that represent clean, intermediate, and polluted conditions, respectively. Details of the LES model and the case are given in Xue and Feingold (2006). Precipitation is light in the clean case and negligible in the intermediate and polluted cases. We choose different aerosol concentrations to see if the $r_{\mathrm{e}}$ profiles have different characteristics under non-precipitating and drizzling conditions. $r_{\mathrm{e}}$ is calculated based on the droplet size distribution that is represented by 33 bins from $1-2500 \mu \mathrm{m}$ radius. The large-eddy simulations were performed in a doubly periodic, $6.4 \mathrm{~km} \times 6.4 \mathrm{~km} \times 3 \mathrm{~km}$ domain. The model gridspacing is $\Delta x=\Delta y=100 \mathrm{~m}$, and $\Delta z=40 \mathrm{~m}$. All the simulations were run for six hours, but analysis was only performed over the last four hours. Model output was sampled every 5 min, thus 48 snapshots in the last four hours of simulation in each case were analyzed.

The areas where LWP exceeds $10 \mathrm{~g} \mathrm{~m}^{-2}$ are considered as cloudy areas. We define cloud-top $r_{\mathrm{e}}$ in each cloudy column as the $r_{\mathrm{e}}$ at the highest grid point that has liquid water mixing ratio $q_{1}>0.01 \mathrm{~g} \mathrm{~kg}^{-1}$. We use the cloud-top $r_{\mathrm{e}}$ and the corresponding cloud-top height from the modeled cloud ensembles in 48 snapshots to construct an $r_{\mathrm{e}}$ profile. This constructed $r_{\mathrm{e}}$ profile is then compared to the $r_{\mathrm{e}}$ profile from all cloud samples in the 48 snapshots. The purpose is to test if the cloud-top $r_{\mathrm{e}}$, measured from satellites, can represent the $r_{\mathrm{e}}$ well in clouds at the same height for convective clouds. Because cloud-top droplet size is usually affected by entrainment mixing, we also add two additional measures of cloudtop $r_{\mathrm{e}}$ to the analyses: one is the $r_{\mathrm{e}}$ at one grid below the highest grid point that has $q_{1}>0.01 \mathrm{~g} \mathrm{~kg}^{-1}$; the other is the maximum $r_{\mathrm{e}}$ in the column (usually several grid points below the highest grid point that has $q_{1}>0.01 \mathrm{~g} \mathrm{~kg}^{-1}$ ). Results using different definitions of cloud-top $r_{\mathrm{e}}$ will be discussed in Sect. 3. The plane-parallel radiative transfer model SBDART (Santa Barbara DISTORT Atmospheric Radiative Transfer; Ricchiazzi et al., 1998) is used to investigate the shortwave radiative forcing of shallow cumulus clouds. The focus is on the effect of cloud vertical inhomogeneity, and so we ignore three-dimensional radiative effects, which were addressed by Zuidema et al. (2008). Because the simulated cumulus clouds cover heights between $z=600 \mathrm{~m}$ and $z=2200 \mathrm{~m}$, but most clouds have cloud tops lower than $z=1600 \mathrm{~m}$, we use a solid cloud layer covering the height of $z=600-1600 \mathrm{~m}$ in the SBDART model. The vertical inhomogeneity of the solid cloud layer is represented by 5 sublayers, each of which has a depth of $200 \mathrm{~m}$. The liquid water content (LWC) and $r_{\mathrm{e}}$ of each sublayer is an average of the LES results in that layer for each of the simulated cases. We compare the shortwave radiative forcing of the vertically inhomogeneous clouds with that of the vertically homogeneous clouds that have the same LWP. The SBDART model also requires setup of the atmospheric profile, aerosols, surface model, etc. We select the tropical atmospheric profile, which is one of the six standard atmospheric profiles in the model. The aerosol optical depth in the cloud-free atmosphere is simply set to zero because we only investigate the difference of radiative forcings from a vertically homogeneous cloud and a vertically inhomogeneous cloud. The surface model in SBDART is selected as ocean water. Solar zenith angle is varied from 0-90 degrees but only results for the 60 degree are shown here. We investigate the effect of cloud vertical inhomogeneity on the radiative forcing over the wavelength range of $0.25-4.0 \mu \mathrm{m}$.

\section{Results}

\section{1 $r_{\mathrm{e}}$ profiles of cloud population}

Figure 1 shows $r_{\mathrm{e}}$ profiles of the cloud population over the last $4 \mathrm{~h}$ of simulation. The $r_{\mathrm{e}}$ profiles from all cloud samples in each case are shown in Fig. 1a-c, and the 50th percentile of the $r_{\mathrm{e}}$ is shown as a reference (black lines). In the polluted and intermediate cases where precipitation is suppressed, $r_{\mathrm{e}}$ increases with height and also exhibits variability at each level (Fig. 1a, b). In the clean case where precipitation develops, $r_{e}$ generally increases with height but with significantly higher variability at all levels (Fig. 1c). The $r_{e}$ profile is complicated in the clean case due to droplet collision-coalescence and sedimentation. Note that for clarity the drizzle-mode drops larger than $50 \mu \mathrm{m}$ radius (both inside of the clouds and below the cloud base) in the clean case are not shown (the scale of the $\mathrm{x}$-axis is set to $50 \mu \mathrm{m}$ ).

The constructed $r_{\mathrm{e}}$ profiles using cloud-top $r_{\mathrm{e}}$ are shown in Fig. 1d-f. The 50th percentile of the $r_{\mathrm{e}}$ from all cloud 

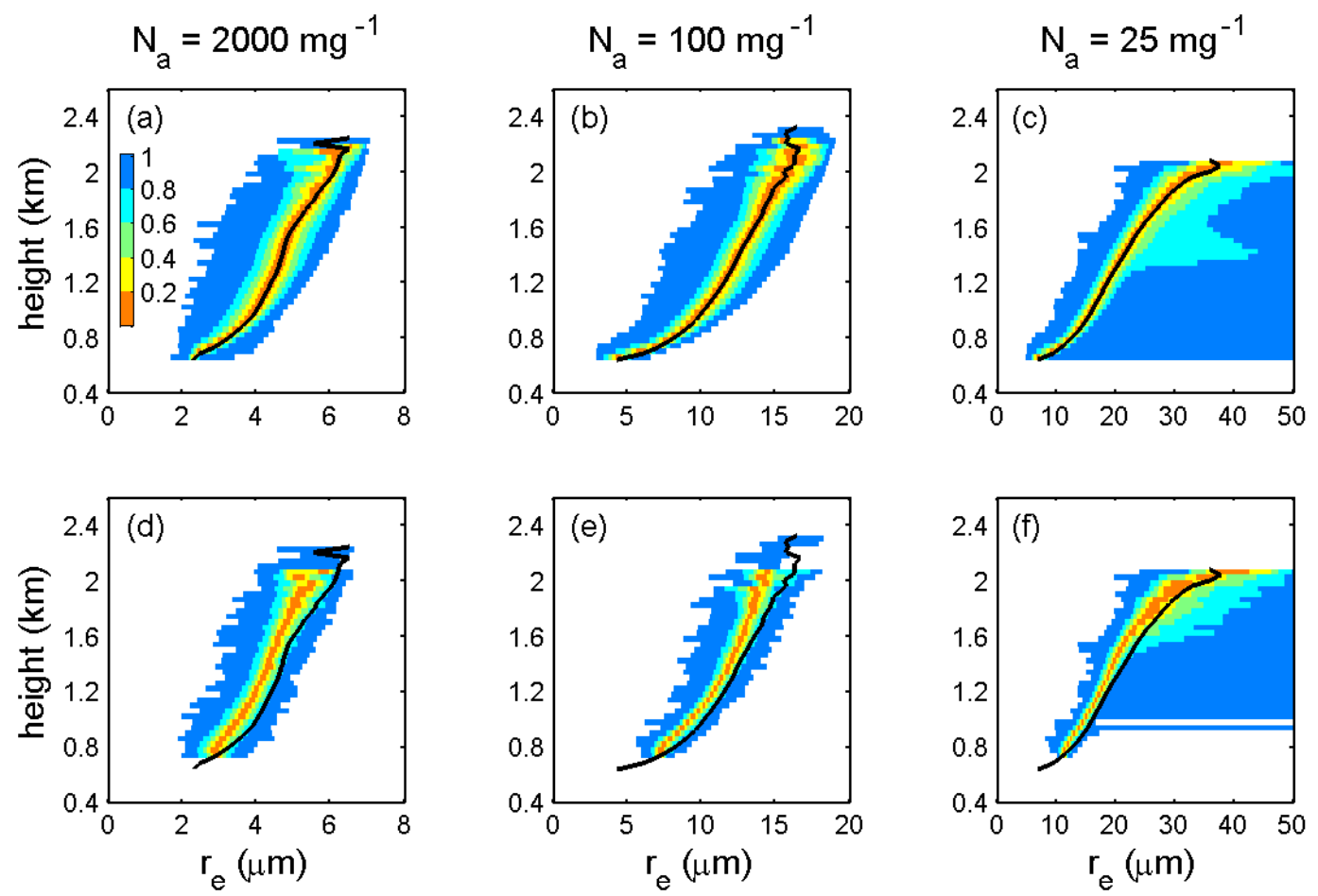

Fig. 1. $r_{\mathrm{e}}$ profiles of cloud population in the last $4 \mathrm{~h}$ of simulation in the polluted $\left(N_{\mathrm{a}}=2000 \mathrm{mg}^{-1}\right)$, intermediate $\left(N_{\mathrm{a}}=100 \mathrm{mg}^{-1}\right)$, and clean $\left(N_{\mathrm{a}}=25 \mathrm{mg}^{-1}\right)$ cases. $(\mathbf{a}, \mathbf{b}, \mathbf{c}) r_{\mathrm{e}}$ profiles from all cloud samples. (d, e, f) Constructed $r_{\mathrm{e}}$ profiles using cloud-top $r_{\mathrm{e}}$. Different colors represent different percentiles. (Orange: 40-60 percentiles; yellow: 30-40, 60-70 percentiles; green: 20-30, 70-80 percentiles; cyan: 10-20, 80-90 percentiles; blue: 0-10, 90-100 percentiles.) Notice that data points are few near cloud top so that only blue is used to represent $0-100$ percentiles. The drizzle mode drops (larger than 50 microns) in clouds and below cloud base are not shown in the clean case for clarity. The 50th percentile of the $r_{\mathrm{e}}$ from all cloud samples in each case are shown for reference (black lines).

samples is also shown as a reference (black lines). The constructed $r_{\mathrm{e}}$ profiles have similar properties to the $r_{\mathrm{e}}$ profiles from all cloud samples, although with a low bias (as can be seen from the median $r_{\mathrm{e}}$ in the constructed $r_{\mathrm{e}}$ profile compared to the 50th percentile of $r_{\mathrm{e}}$ from all cloud samples in each case). This bias is about $0.5 \mu \mathrm{m}(\sim 10 \%)$ in the polluted case, $1 \mu \mathrm{m}(\sim 10 \%)$ in the intermediate case, and $2 \mu \mathrm{m}$ $(\sim 10 \%)$ in the clean case. The constructed $r_{\mathrm{e}}$ does represent the in-cloud $r_{\mathrm{e}}$ in the polluted and intermediate cases fairly well, with a low bias $(\sim 10 \%)$, providing evidence that the cloud-top $r_{\mathrm{e}}$ from satellite measurements can generally be used for profiling $r_{\mathrm{e}}$. Therefore the method used in Rosenfeld and Lensky (1998) is validated in this study for shallow cumulus. For precipitating clouds, the significant variability suggests that cloud-top $r_{\mathrm{e}}$ from satellite measurements may be unreliable.

As expected, both the $r_{\mathrm{e}}$ profiles from all cloud samples and the constructed $r_{\mathrm{e}}$ profiles in Fig. 1 indicate that $r_{\mathrm{e}}$ becomes larger when aerosol mixing ratio changes from $2000 \mathrm{mg}^{-1}$, to $100 \mathrm{mg}^{-1}$, and to $25 \mathrm{mg}^{-1}$ (Twomey, 1974). Results indicate that $r_{\mathrm{e}}$ variability in the polluted and intermediate cases is relatively small compared to the aerosol effects on $r_{\mathrm{e}}$. Although $r_{\mathrm{e}}$ variability in the clean case is large, the three cases still show distinct differences in $r_{\mathrm{e}}$ for the relatively large range in aerosol conditions considered here. Successfully distinguishing the differences in $r_{\mathrm{e}}$ between clean and polluted air masses using satellite retrievals or other measurements will depend on the existing aerosol gradient and the accuracy of the remote $r_{\mathrm{e}}$ retrieval.

Figure 2 shows the constructed $r_{\mathrm{e}}$ profiles using different measures of cloud-top $r_{\mathrm{e}}$. Results using the $r_{\mathrm{e}}$ at one grid point below the highest grid that has $q_{1}>0.01 \mathrm{~g} \mathrm{~kg}^{-1}$ are shown in Fig. 2a-c. The constructed $r_{\mathrm{e}}$ profiles closely represent the in-cloud $r_{\mathrm{e}}$, especially in the polluted and intermediate cases. Figure $2 \mathrm{~d}-\mathrm{f}$ presents constructed $r_{\mathrm{e}}$ profiles with the maximum $r_{\mathrm{e}}$ in each column. The $r_{\mathrm{e}}$ profiles constructed in this way have a high bias $(\sim 5 \%)$ compared to the in-cloud $r_{\mathrm{e}}$. Therefore, the constructed $r_{\mathrm{e}}$ profiles show progressively larger $r_{\mathrm{e}}$ when using the following measures of cloud-top $r_{\mathrm{e}}$ : (1) $r_{\mathrm{e}}$ at the highest grid point with $q_{\mathrm{l}}>0.01 \mathrm{~g} \mathrm{~kg}^{-1}$; (2) $r_{\mathrm{e}}$ at one grid point below the highest grid with $q_{1}>0.01 \mathrm{~g} \mathrm{~kg}^{-1}$; and (3) the maximum $r_{\mathrm{e}}$ in the column. In addition, the constructed $r_{\mathrm{e}}$ profiles using different measures of cloud-top $r_{\mathrm{e}}$ still show the aerosol effects on $r_{\mathrm{e}}$ and the distinction between clean, intermediate, and polluted conditions, similar to results in Fig. 1. 

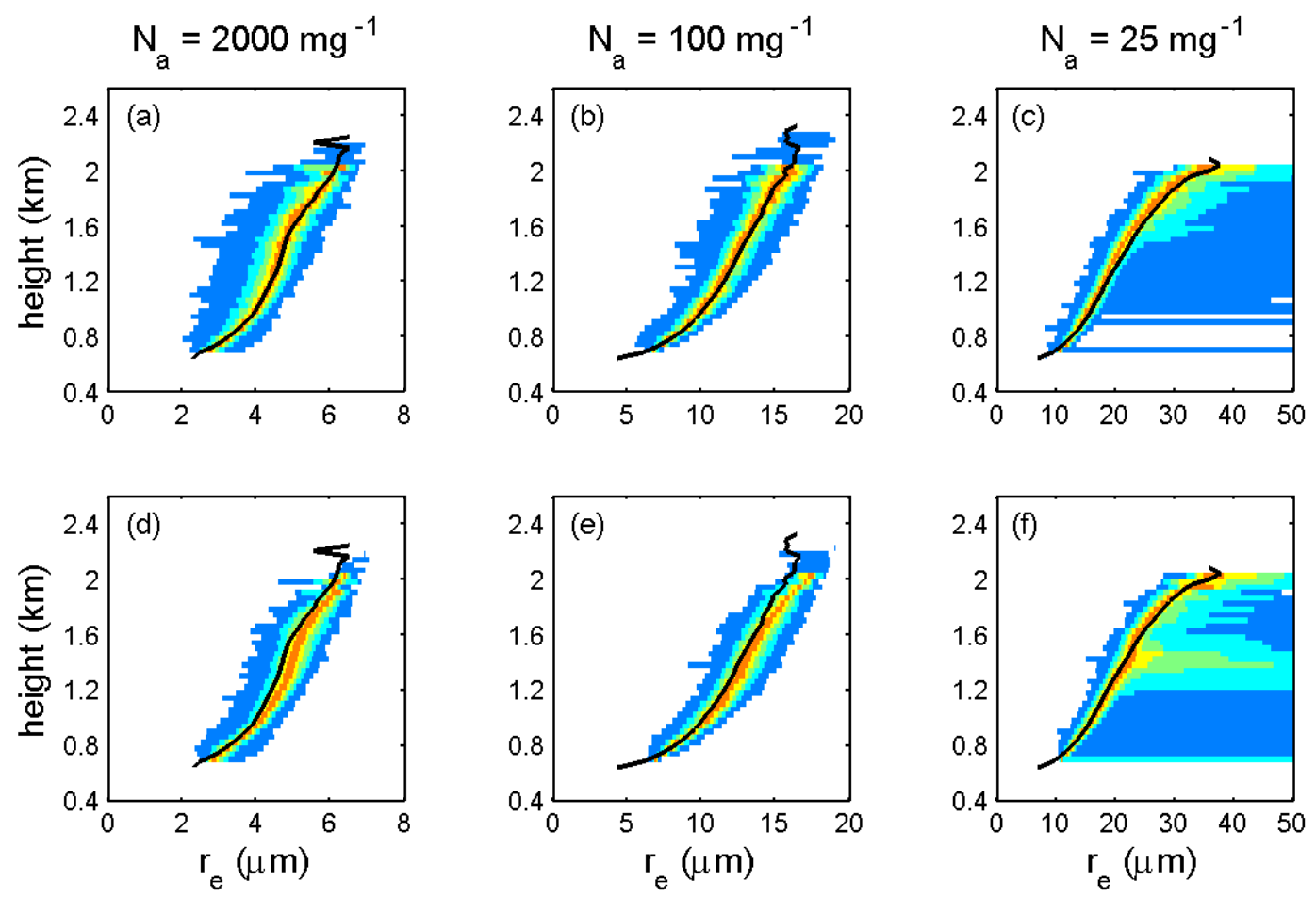

Fig. 2. Constructed $r_{\mathrm{e}}$ profiles using different measures of cloud-top $r_{\mathrm{e}}$. (a, $\left.\mathbf{b}, \mathbf{c}\right)$ Using $r_{\mathrm{e}}$ at one grid point below the highest grid that has $q_{1}>0.01 \mathrm{~g} \mathrm{~kg}^{-1}$. (d, e, f) Using maximum $r_{\mathrm{e}}$ in the column. Color scale is the same as Fig. 1. The 50th percentile of the $r_{\mathrm{e}}$ from all cloud samples in each case are shown for reference (black lines, same as Fig. 1).

The modeled $r_{\mathrm{e}}$ at the uppermost grid point is smaller than that well in cloud at the same height, partly because the model assumes homogeneous mixing. For real clouds that have both homogeneous and inhomogeneous mixing, the cloud-top $r_{\mathrm{e}}$ should be closer to the in-cloud $r_{\mathrm{e}}$ at the same height. Thus the bias in profiling the in-cloud $r_{\mathrm{e}}$ is likely less than $10 \%$ using the Rosenfeld and Lensky (1998) method. Another reason for the smaller $r_{\mathrm{e}}$ at the uppermost grid point is that the grid may be overly diluted in the model. At the cloud boundary (for example, the cloud top), the model tends to over-dilute the cloud because of the limited model resolution. It is possible that an uppermost grid point of the cloud is considered as cloudy in the model, while it is only partially filled with cloud in reality. The modeled cloud would then have lower LWC compared to the real cloud. However, regardless of the model performance on this issue, the uppermost grid point would be more diluted as compared with the lower grid points because of the mixing process. Detailed discussion of the effect of entrainment mixing on the $r_{\mathrm{e}}$ profile and its evolution will be given in Sect. 3.3.

\subsection{Evolution of $r_{\mathrm{e}}$ profiles of individual clouds}

Figure 3 shows the evolution of $r_{\mathrm{e}}$ profiles of individual clouds at different stages of their lifetime in the simulated cases. We focus on individual clouds that are bigger but do not merge with other clouds or break up into smaller ones throughout their lifetime. Only three $r_{\mathrm{e}}$ profiles during the development of each cloud are shown here. The $r_{\mathrm{e}}$ profiles of an individual cloud evolving for $40 \mathrm{~min}$ in the polluted case are shown in Fig. 3a. The cloud starts to grow from $3 \mathrm{~h} 15 \mathrm{~m}$, increases to the maximum height at $3 \mathrm{~h} 35 \mathrm{~m}$, and completely dissipates after $3 \mathrm{~h} 55 \mathrm{~m}$. It is interesting that the cloud-top $r_{\mathrm{e}}$ is smaller at $3 \mathrm{~h} 25 \mathrm{~min}$ (growing) and $3 \mathrm{~h} 45 \mathrm{~min}$ (decaying) compared to the $r_{\mathrm{e}}$ at the same heights at $3 \mathrm{~h} 35 \mathrm{~min}$ (growing and reaching maximum height). The $r_{\mathrm{e}}$ profile at $3 \mathrm{~h} 35 \mathrm{~min}$ seems to fill in the cloud-top $r_{\mathrm{e}}$ of the lower clouds. In addition, the decaying cloud ( $3 \mathrm{~h} 45 \mathrm{~min}$ ) has slightly smaller $r_{\mathrm{e}}$ than the growing cloud reaching maximum height ( $3 \mathrm{~h} 35 \mathrm{~min}$ ). These characteristics of $r_{\mathrm{e}}$ profiles during cloud development may be explained by a combination of the effects of preconditioning and mixing on $r_{\mathrm{e}}$, as discussed in detail in Sect. 3.3.

Figure $3 \mathrm{~b}$ shows a cloud in the intermediate case that starts to grow from $4 \mathrm{~h} 10 \mathrm{~min}$ and completely dissipates after $4 \mathrm{~h} 35 \mathrm{~min}$. It grows to its maximum height at $4 \mathrm{~h} 30 \mathrm{~min}$. Similarly, the $r_{\mathrm{e}}$ at $4 \mathrm{~h} 30 \mathrm{~min}$ seems to fill in the cloud-top $r_{\mathrm{e}}$ of the lower clouds at the other two times. The $r_{\mathrm{e}}$ of the decaying cloud ( $4 \mathrm{~h} 35 \mathrm{~min}$ ) is also slightly smaller than those of the growing clouds ( $4 \mathrm{~h} 20 \mathrm{~min}$ and $4 \mathrm{~h} 30 \mathrm{~min}$ ).

The evolution of a cloud in the clean case is more complicated (Fig. 3c). The cloud evolves from $2 \mathrm{~h} 30 \mathrm{~min}$ to 

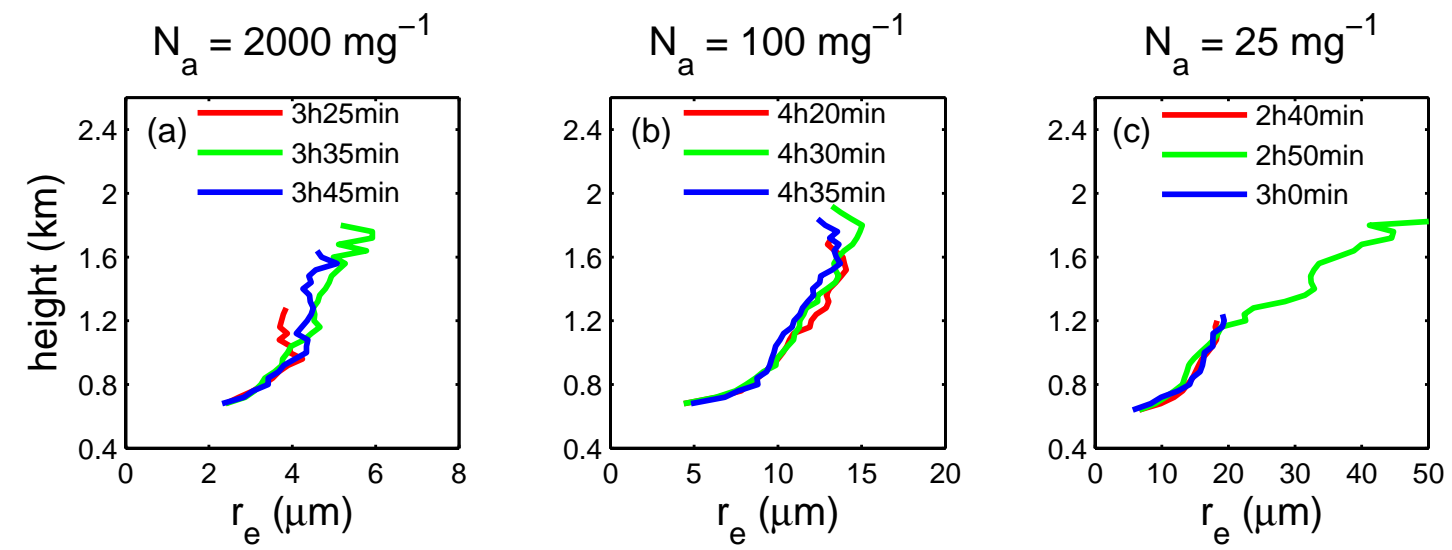

Fig. 3. Evolution of $r_{\mathrm{e}}$ profiles of individual clouds throughout their lifetime in each case. (a) A cloud in the polluted case evolving from $3 \mathrm{~h} 15 \mathrm{~min}$ to $3 \mathrm{~h} 55 \mathrm{~min}$. The cloud reaches the maximum height at $3 \mathrm{~h} 35 \mathrm{~min}$. (b) A cloud in the intermediate case from $4 \mathrm{~h} 10 \mathrm{~min}$ to $4 \mathrm{~h} 35 \mathrm{~min}$, reaching the maximum height at $4 \mathrm{~h} 30 \mathrm{~min}$. (c) A cloud in the clean case from $2 \mathrm{~h} 30 \mathrm{~min}$ to $3 \mathrm{~h} 5 \mathrm{~min}$. It reaches the maximum height at $2 \mathrm{~h} 50 \mathrm{~min}$. Only the $r_{\mathrm{e}}$ profile at the time with the maximum height, and two profiles before and after the maximum height are shown.

$3 \mathrm{~h} 5 \mathrm{~min}$. At $2 \mathrm{~h} 50 \mathrm{~min}$, large drops form due to collisioncoalescence. We can clearly see the condensation regime at a height of $0.7-1.2 \mathrm{~km}$ near cloud base where droplet growth is relatively slow, and the coalescence regime at the height of $1.2-1.8 \mathrm{~km}$ where the growth is much faster (Rosenfeld and Lensky, 1998). This confirms the findings in Figs. 1 and 2 that, for clouds that are precipitating, it is difficult to use the cloud-top $r_{\mathrm{e}}$ to infer the in-cloud $r_{\mathrm{e}}$.

\subsection{Difference of $r_{\mathrm{e}}$ profiles in growing and decaying clouds}

The cloud population over the last $4 \mathrm{~h}$ of simulation in each case is divided into growing clouds and decaying clouds based on a criterion of maximum vertical velocity. A cloud is considered as a growing (decaying) cloud if its maximum vertical velocity is higher (lower) than $2 \mathrm{~m} \mathrm{~s}^{-1}$. Ideally a cloud that has a maximum vertical velocity smaller than $0 \mathrm{~m} \mathrm{~s}^{-1}$ might be considered a decaying cloud. However, we note that using the $0 \mathrm{~m} \mathrm{~s}^{-1}$ criterion leads to very few samples for decaying clouds, and that using the $1 \mathrm{~m} \mathrm{~s}^{-1}$, and $2 \mathrm{~m} \mathrm{~s}^{-1}$ criteria provides progressively more samples. The difference of $r_{\mathrm{e}}$ profiles in the growing and decaying clouds is very similar when using these three criteria. Figure 4 shows the $r_{\mathrm{e}}$ profiles in growing and decaying clouds using the criterion of a $2 \mathrm{~m} \mathrm{~s}^{-1}$ maximum vertical velocity. The 50th percentile of $r_{\mathrm{e}}$ from all cloud samples in each case is also shown as a reference (black lines). It is seen that, for the non-precipitating polluted and intermediate cases, $r_{\mathrm{e}}$ is generally smaller in the decaying clouds than in the growing clouds, probably because of progressively stronger entrainment mixing, as will be discussed next. In the polluted case, $r_{\mathrm{e}}$ in the decaying stage is about $0.5 \mu \mathrm{m}$ smaller than that in the growing clouds. Similarly, in the intermediate case, $r_{\mathrm{e}}$ in the decaying clouds is about $1 \mu \mathrm{m}$ smaller than that in the growing clouds. The clean case has large drops in both the growing and decaying stages because large drops form due to collision-coalescence as clouds develop into mature and decaying stages.

Because the above results show that cloud-top $r_{\mathrm{e}}$ is slightly smaller than the in-cloud $r_{\mathrm{e}}$ (Fig. 1), and that $r_{\mathrm{e}}$ in a decaying cloud is smaller than that in a growing cloud (Figs. 3 and 4), we now investigate the effects of entrainment mixing on $r_{\mathrm{e}}$ and its evolution. We use the adiabatic fraction $f_{\text {ad }}$, defined as the ratio between the simulated cloud water to the adiabatic value (e.g., Pawlowska et al., 2006), to represent the subadiabatic characteristics of clouds. Note that our LES model uses time-splitting between dynamical and microphysical processes and therefore implicitly assumes the homogeneous mixing process. Our investigation here represents a situation where $r_{\mathrm{e}}$ of convective clouds may be affected by mixing to the maximum extent (extremely homogeneous mixing). On the other hand, for adiabatic clouds or an extremely inhomogeneous mixing situation, cloud-top $r_{\mathrm{e}}$ should be the same as the in-cloud $r_{\mathrm{e}}$ at the same height. Freud et al. (2008) found that $r_{\mathrm{e}}$ shows small variability when looking at a nearly constant height for convective clouds (up to the freezing level), suggesting inhomogeneous mixing in the clouds. For a cloud that experiences both homogeneous and inhomogeneous mixing processes (Lehmann et al., 2009), the effect of mixing on $r_{\mathrm{e}}$ should lie between the extreme situations discussed above. The nature of the entrainment mixing may also change as the cloud evolves. Whether cumulus clouds experience homogeneous mixing or inhomogeneous mixing is not the focus of this study. However, a previous study has shown that assuming extreme inhomogeneous rather than homogeneous mixing results in a small $(2 \%-5 \%)$ reduction in cloud-averaged droplet number 

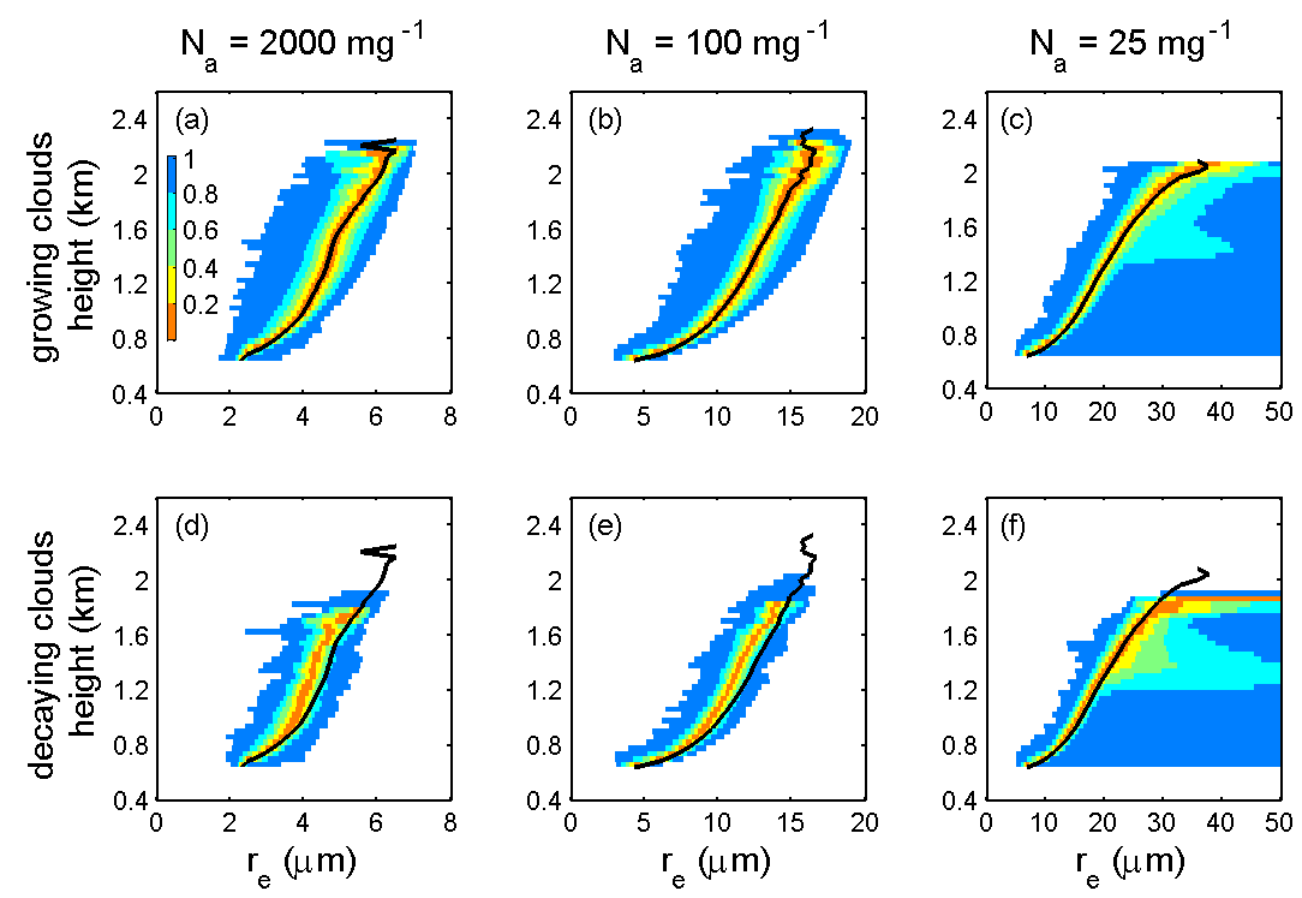

Fig. 4. $r_{\mathrm{e}}$ profiles from different cloud samples in the last $4 \mathrm{~h}$ of simulation for the three cases. (a, b, c) Growing clouds, maximum $w>2.0 \mathrm{~m} \mathrm{~s}^{-1}$; (d, e, f) decaying clouds, maximum $w<2.0 \mathrm{~m} \mathrm{~s}^{-1}$. Black lines are the 50th percentiles of the $r_{\mathrm{e}}$ from all cloud samples for reference (same as in Fig. 1). Color scale is the same as Fig. 1.

concentration and a commensurately small increase in $r_{\mathrm{e}}$ for marine stratocumulus clouds (Hill et al., 2008).

Figure 5 shows vertical profiles of $f_{\text {ad }}$ in the three simulated cases. It is seen that $f_{\text {ad }}$ is significantly smaller than 1 . In the lower layer of the clouds (from cloud base to about $0.8 \mathrm{~km}), f_{\text {ad }}$ increases with height. Above this layer, $f_{\text {ad }}$ generally decreases with height to about $1.6 \mathrm{~km}$. Because the cloud population is dominated by clouds that are several hundred meters deep in the simulated cases, the fact that $f_{\text {ad }}$ decreases from 0.8 to $1.6 \mathrm{~km}$ indicates that liquid water mixing ratio in cloud samples near cloud top is reduced by entrainment, as revealed in observations (e.g., Warner, 1955; Blyth et al., 1988; Blyth, 1993; Miles et al., 2000; Small and Chuang, 2008). The characteristics of the bigger clouds are averaged out by the smaller clouds in this layer. From $1.6 \mathrm{~km}$ to about $2 \mathrm{~km}$, the increased $f_{\text {ad }}$ at cloud top in each case is due to the few bigger and deeper clouds that have higher $f_{\text {ad }}$. It is also likely that these larger clouds are growing in preconditioned, moistened air and that drops in this region are less prone to evaporation. Notice that for the polluted and intermediate cases where precipiation is negligible, $f_{\text {ad }}$ generally represents the degree of mixing. But in the clean case where precipitation develops, deviation from adiabatic liquid water content is not only affected by mixing, but also by drop sedimentation. The removal of liquid water by sedimentation is probably the reason that $f_{\text {ad }}$ is relatively low in the clean case compared to the other two cases.
Figure 6 shows the $f_{\text {ad }}$ evolution of the individual clouds discussed in Fig. 3. It is seen that $f_{\text {ad }}$ generally decreases, representing stronger entrainment mixing, as the individual clouds grow and dissipate. The enhanced degree of mixing during cloud development can cause a slight decrease in $r_{\mathrm{e}}$, as can be seen in Fig. 3. It should be noted that the decrease in $f_{\text {ad }}$ is not monotonic, and shows evidence of pulsating growth as discussed in Heus et al. (2009). Although the LES model output in this study is sampled only every $5 \mathrm{~min}$, which is similar to the time scale of pulses, the nonmonotonic evolution of $f_{\text {ad }}$ is consistent with the concept that a cloud can be seen as a sequence of pulses (French et al., 1999; Heus et al., 2009).

Cloud samples are divided into three regimes based on $f_{\text {ad }}$ : sub-adiabatic $\left(0.5<f_{\text {ad }}<1.0\right)$, strongly diluted $\left(0.1<f_{\text {ad }}<0.5\right)$, and very strongly diluted $\left(0<f_{\text {ad }}<0.1\right)$ cloud samples. $r_{\mathrm{e}}$ profiles in the three $f_{\text {ad }}$ regimes are shown in Fig. 7. $r_{\mathrm{e}}$ in sub-adiabatic cloud samples $\left(0.5<f_{\mathrm{ad}}<1.0\right)$ are generally larger than the median $r_{\mathrm{e}}$ of all cloud samples (Fig. 7a-c), while $r_{\mathrm{e}}$ in very strongly diluted cloud samples $\left(0<f_{\text {ad }}<0.1\right)$ are generally smaller than the median $r_{\mathrm{e}}$ of all cloud samples (Fig. 7g-i). $r_{\mathrm{e}}$ generally becomes smaller as $f_{\text {ad }}$ decreases, showing that smaller $r_{\mathrm{e}}$ is caused by more entrainment mixing, especially for the nonprecipitating polluted and intermediate cases. The degree of $r_{\mathrm{e}}$ variability is also highly correlated with the degree of mixing. Note that most cloud samples are strongly diluted $\left(0.1<f_{\text {ad }}<0.5\right)$. However, it is in the very strongly diluted 

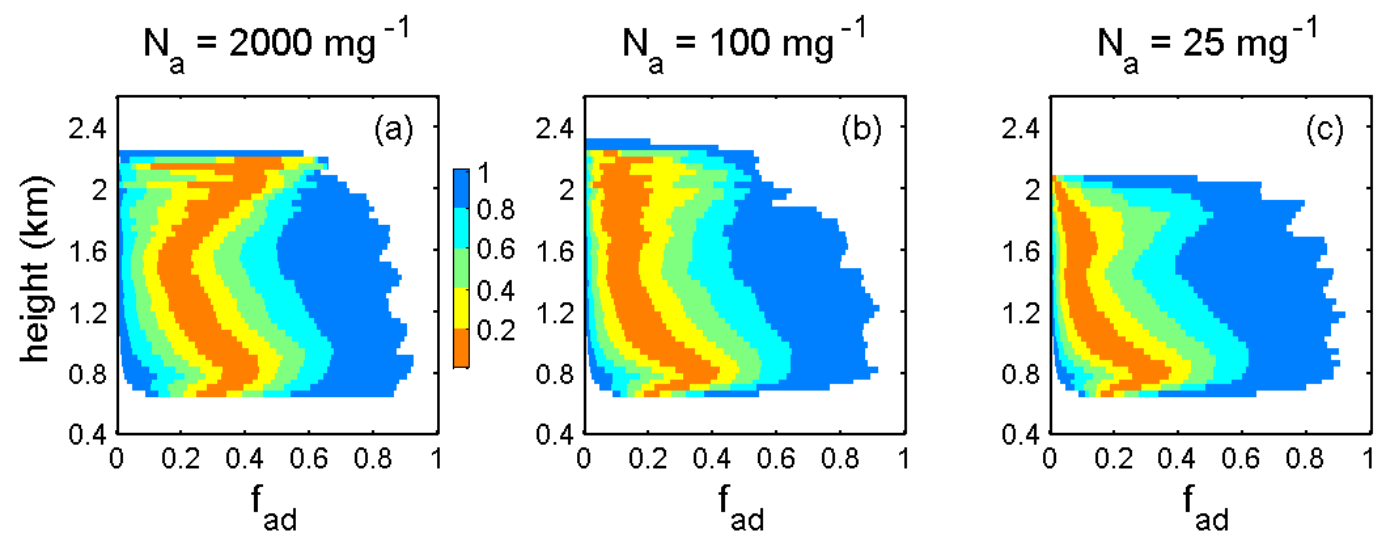

Fig. 5. Averaged profiles of adiabatic fraction $\left(f_{\mathrm{ad}}\right)$ over the last $4 \mathrm{~h}$ of simulation for the three cases. Color scale is the same as Fig. 1.
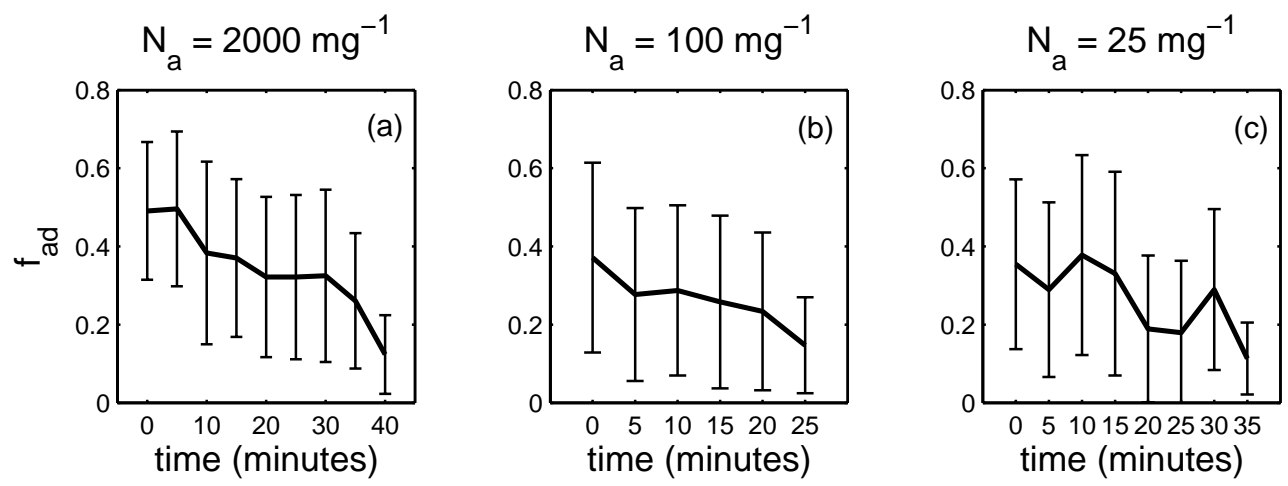

Fig. 6. Evolution of $f_{\text {ad }}$ for the individual clouds shown in Fig. 3.

regime $\left(0<f_{\text {ad }}<0.1\right)$ that $r_{\mathrm{e}}$ has the highest variability. $r_{\mathrm{e}}$ in the subadiabatic regime $\left(0.5<f_{\text {ad }}<1.0\right)$ has small variability. For the clean, precipitating case, the strongly diluted and very strongly diluted cloud samples have drops that are much larger than the median $r_{\mathrm{e}}$ due to droplet collision-coalescence and sedimentation. We do not discuss mixing effects for the clean case as $f_{\text {ad }}$ cannot be used as an approximation for the degree of mixing in this case.

\subsection{Effect of vertical inhomogeneity on shortwave radiative forcing}

The vertical profiles of LWC and $r_{\mathrm{e}}$ used in the SBDART model are shown in Fig. 8. Profiles for the vertically inhomogeneous clouds are based on the LES simulations. The LWC of the vertically homogeneous cloud is chosen in the way that the two clouds have the same LWP. We vary the $r_{\mathrm{e}}$ of the vertically homogeneous cloud until the two clouds have the same radiative forcing. The $r_{\mathrm{e}}$ of the vertically homogeneous cloud, along with the cloud-top $r_{\mathrm{e}}$ of the vertically inhomogeneous cloud (as in Fig. 8), are listed in Table 1 . Shortwave radiative forcing both at the surface and at TOA are investigated. It is seen that the $r_{\mathrm{e}}$ of the vertically homogeneous cloud must be about $76-90 \%$ of the $r_{\mathrm{e}}$ at the top of the vertically inhomogeneous cloud in order for them to have the same shortwave radiative forcing. The smaller values $(\sim 76 \%)$ are associated with clean clouds that exhibit large vertical variation in $r_{\mathrm{e}}$ while the larger values $(\sim 90 \%)$ are for polluted clouds with small vertical variation in $r_{\mathrm{e}}$. Results in this study are consistent with previous findings on stratified clouds (Brenguier et al., 2003).

\section{Conclusions}

Analyses of $r_{\mathrm{e}}$ profiles in shallow convective clouds simulated with LES show that in-cloud $r_{\mathrm{e}}$ increases with height for polluted $\left(N_{\mathrm{a}}=2000 \mathrm{mg}^{-1}\right)$ and intermediate $\left(N_{\mathrm{a}}=100 \mathrm{mg}^{-1}\right)$ aerosol conditions. Under clean conditions $\left(N_{\mathrm{a}}=25 \mathrm{mg}^{-1}\right)$, the in-cloud $r_{\mathrm{e}}$ has high variability at each level. Cloud-top $r_{\mathrm{e}}$ of the modeled cloud ensembles, each with a different cloud-top height and at a different stage of development, was used to construct a profile of $r_{\mathrm{e}}$. It is seen that, on average, the cloud-top $r_{\mathrm{e}}$ is in agreement with the in-cloud $r_{\mathrm{e}}$ at the same height for the polluted and intermediate cases, but with a low bias (about 10\%). This bias is alleviated if one uses $r_{\mathrm{e}}$ at one grid below the cloud top. Thus the assumption used by Rosenfeld and Lensky (1998) 

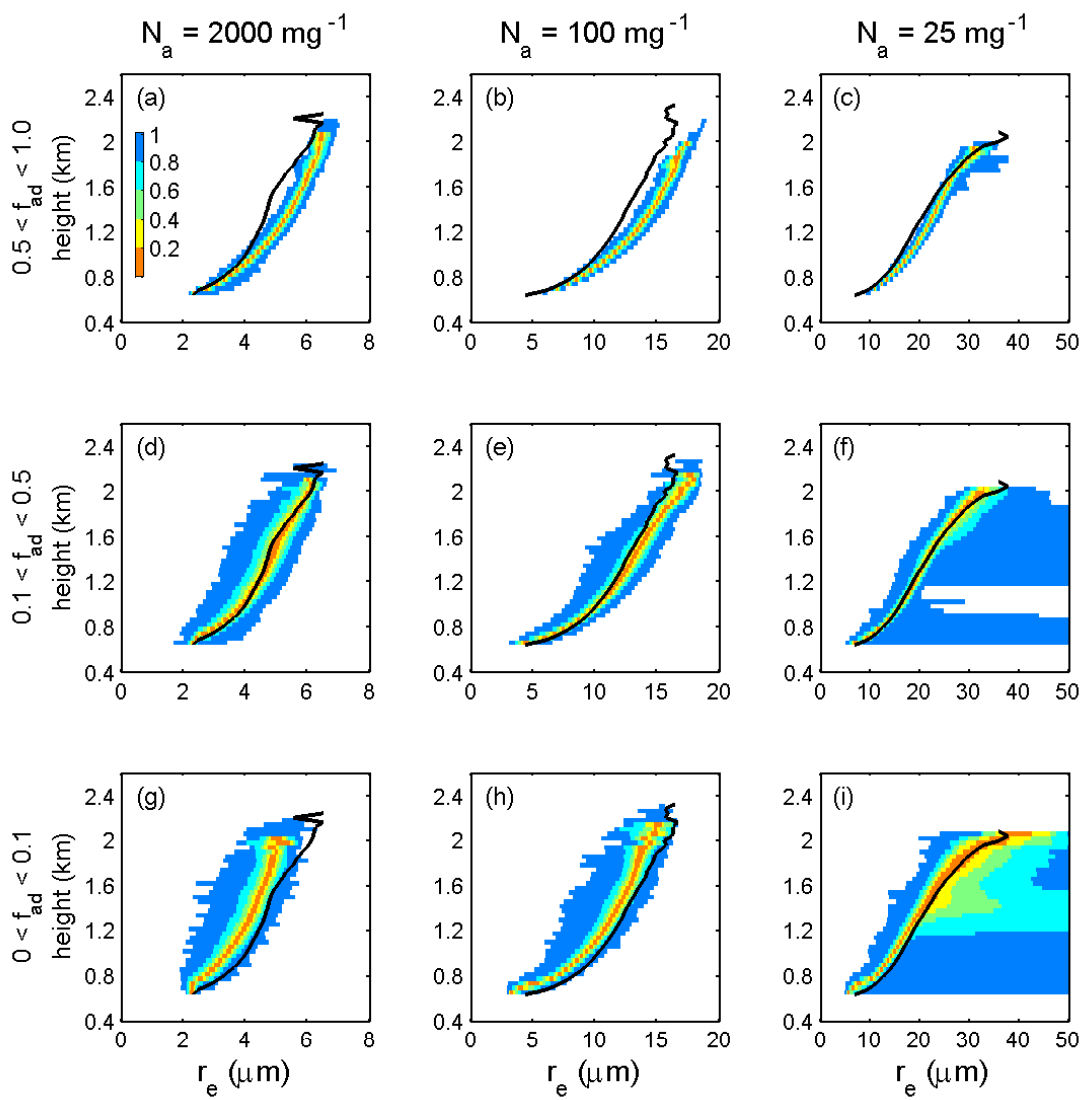

Fig. 7. $r_{\mathrm{e}}$ profiles from different cloud samples over the last $4 \mathrm{~h}$ of simulation for the three cases. (a, b, c) Sub-adiabatic regime $(0.5<$ $\left.f_{\text {ad }}<1.0\right)$; (d, e, f) strongly diluted regime $\left(0.1<f_{\text {ad }}<0.5\right)$; (g, h, i) very strongly diluted regime $\left(0<f_{\text {ad }}<0.1\right)$. Black lines are the 50 th percentiles of the $r_{\mathrm{e}}$ from all cloud samples for reference (same as in Fig. 1). Color scale is the same as Fig. 1.
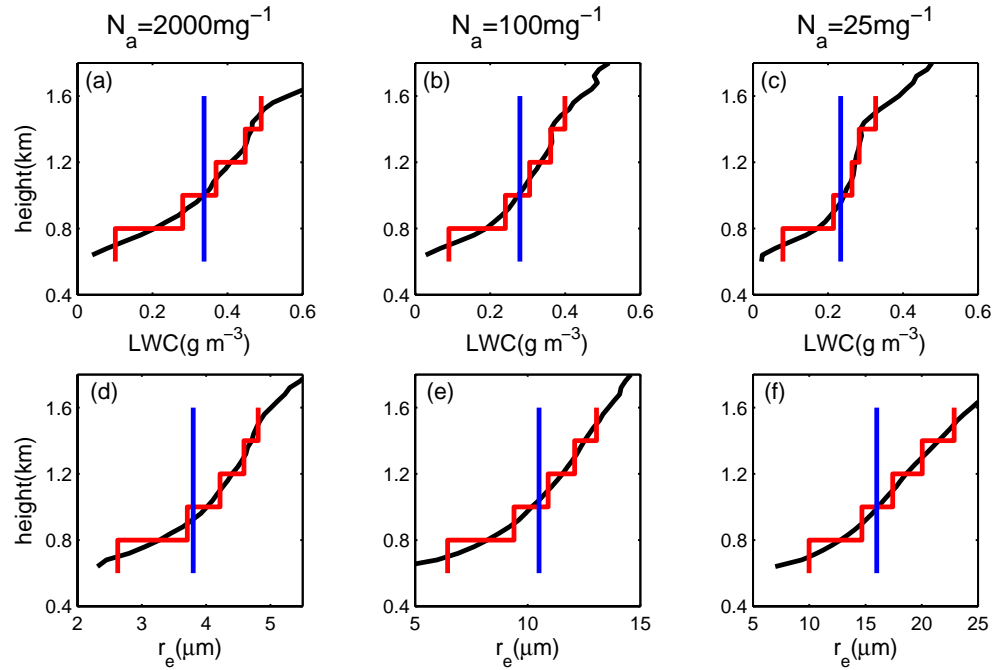

Fig. 8. (a, b, c) Idealized LWC profiles and $(\mathbf{d}, \mathbf{e}, \mathbf{f})$ idealized $r$ e profiles for the input of the SBDART model. Black lines: LES model results. Red lines: vertically inhomogeneous clouds that have 5 sublayers covering the height range $z=600-1600 \mathrm{~m}$; profiles are based on LES simulations. Blue lines: vertically homogeneous clouds. Note that the two clouds have the same LWP. We vary the $r_{\mathrm{e}}$ of the vertically homogeneous cloud (shown here is one of the values used in the SBDART model for each case) until it has the same radiative forcing as the vertically inhomogeneous cloud. 
Table 1. Comparison of the $r_{\mathrm{e}}$ of the vertically inhomogeneous cloud with that of the vertically homogeneous cloud when two clouds have the same shortwave radiative forcing. Numbers in parentheses represent the ratio of the two. Solar zenith angle is 60 degree.

\begin{tabular}{lccc}
\hline & $N_{\mathrm{a}}=2000 \mathrm{mg}^{-1}$ & $N_{\mathrm{a}}=100 \mathrm{mg}^{-1}$ & $N_{\mathrm{a}}=25 \mathrm{mg}^{-1}$ \\
\hline $\begin{array}{l}r_{\mathrm{e}}(\mu \mathrm{m}) \text { of the highest sublayer in the vertically } \\
\text { inhomogeneous cloud (as in Fig. 8) }\end{array}$ & 4.8 & 13.0 & 22.9 \\
$r_{\mathrm{e}}(\mu \mathrm{m})$ of the vertically homogeneous cloud & $4.2(87.5 \%)$ & $10.8(83.1 \%)$ & $17.5(76.4 \%)$ \\
$\begin{array}{l}\text { when two clouds have the same radiative } \\
\text { forcing at the surface }\end{array}$ & & $11.0(84.6 \%)$ & $18.0(78.6 \%)$ \\
$r_{\mathrm{e}}(\mu \mathrm{m})$ of the vertically homogeneous cloud \\
$\begin{array}{l}\text { when two clouds have the same radiative } \\
\text { forcing at TOA }\end{array}$
\end{tabular}

is confirmed for the modeled shallow convective clouds in this study. This suggests that the cloud-top $r_{\mathrm{e}}$ measured from satellites can be used to represent the in-cloud $r_{\mathrm{e}}$ at the same height with a low bias (about $10 \%$ ) for cumulus clouds that have negligible precipitation. The $10 \%$ low bias is caused by the model assumption of homogeneous mixing, and also by the overly-diluted cloud edges due to model resolution. However, a caveat here is that the cloud sizes would have to fill a remote sensing pixel for these techniques to be useful. In addition, in reality the accuracy would be diminished by instrument and other measurement uncertainties. For the clean case where drizzle develops, $r_{\mathrm{e}}$ profiles are complicated due to droplet collision-coalescence and sedimentation, and hence more difficult to characterize. The constructed $r_{\mathrm{e}}$ profiles in the clean case cannot be used to represent the in-cloud $r_{\mathrm{e}}$ profiles because both the in-cloud $r_{\mathrm{e}}$ and the constructed $r_{\mathrm{e}}$ are highly variable.

This study shows that the ability to distinguish a cloud under a clean aerosol condition from that under a polluted aerosol condition using both the in-cloud $r_{\mathrm{e}}$ and the constructed $r_{\mathrm{e}}$ is good, provided the range of aerosol concentration is high and that the satellite retrieval of $r_{\mathrm{e}}$ is robust. But for relatively small aerosol concentration gradients, the variability of $r_{\mathrm{e}}$ will make it difficult to do so.

Investigation of $r_{\mathrm{e}}$ evolution for individual clouds and the cloud population indicates that $r_{\mathrm{e}}$ becomes smaller (about $10 \%)$ as the cloud develops into the decaying stage. The subadiabatic characteristics of the simulated cases are investigated. The adiabatic fraction $f_{\text {ad }}$ is significantly less than 1 at all heights for the three cases, with the cloud top having smaller $f_{\text {ad }}$, due to stronger entrainment mixing. In addition, $f_{\text {ad }}$ becomes smaller as clouds develop into the decaying stage. The stronger mixing at cloud top and in the decaying stage of the clouds leads to smaller $r_{\mathrm{e}}$. This is the reason why the constructed $r_{\mathrm{e}}$ profiles have a low bias compared to the in-cloud $r_{\mathrm{e}}$, and decaying clouds have smaller $r_{\mathrm{e}}$ than the growing clouds. Results in this paper show that $r_{\mathrm{e}}$ becomes progressively smaller and the variability of $r_{\mathrm{e}}$ also becomes progressively larger as $f_{\text {ad }}$ decreases in the polluted and intermediate cases. It should be noted that $f_{\text {ad }}$ profiles of the smaller and shallower cumulus clouds as investigated in this study may differ from those in larger and deeper clouds. For example, the core regions of deeper clouds may be able to preserve adiabatic LWC. In addition, the mixing in reality is probably not extremely homogeneous as assumed in the model in this study. For the cores of bigger and thicker clouds that have larger $f_{\text {ad }}$, and for clouds that have inhomogeneous mixing (or have both homogeneous and inhomogeneous mixing), the bias in estimating the in-cloud $r_{\mathrm{e}}$ is likely less than $10 \%$ using the method in Rosenfeld and Lensky (1998). However, for the clean, precipitating case, $f_{\text {ad }}$ cannot be used to represent the degree of mixing, because both entrainment mixing and sedimentation affect the distribution of liquid water.

For a vertically homogeneous cloud and a vertically inhomogeneous cloud with the same LWP, $r_{\mathrm{e}}$ of the vertically homogeneous cloud must be about 76-90\% of the cloud-top $r_{\mathrm{e}}$ of the vertically inhomogeneous cloud in order to have the same shortwave radiative forcing. This result for cumulus clouds is consistent with previous studies on stratiform clouds, and indicates that the estimation of cloud shortwave radiative forcing using measured cloud-top $r_{\mathrm{e}}$ needs to be treated carefully.

Acknowledgements. This study was supported by Chinese NSF grant 40675004. GF acknowledges support from NOAA's Climate Goal Program.

Edited by: J. Quaas

\section{References}

Albrecht, B.: Aerosols, cloud microphysics, and fractional cloudiness, Science, 245, 1227-1230, 1989.

Arabas, S., Pawlowska, H., and Grabowski, W. W.: Effective radius and droplet spectral width from in-situ aircraft observations in trade-wind cumuli during RICO, Geophys. Res. Lett., 36, L11803, doi:10.1029/2009GL038257, 2009. 
Arakawa, A. and Schubert, W. H.: Interaction of a cumulus cloud ensemble with large-scale environment, Part one, J. Atmos. Sci., 31, 674-701, 1974.

Blyth, A. M.: Entrainment in cumulus clouds, J. Appl. Meteorol., 32, 626-641, 1993.

Blyth, A. M., Cooper, W. A., and Jensen, J. B.: A study of the source of entrained air in Montana cumuli, J. Atmos. Sci., 45, 3944-3964, 1988.

Breon, F.-M., Tanre, D., and Generoso, S.: Aeorsol effect on cloud droplet size monitored from satellite, Science, 295, 834-838, 2002.

Brenguier, J.-L., Pawlowska, H., Schüller, L., Preusker, R., Fischer, J., and Fouquart, Y.: Radiative properties of boundary layer clouds: Droplet effective radius versus number concentration, J. Atmos. Sci., 57, 803-821, 2000.

Brenguier, J.-L., Pawlowska, H., and Schüller, L.: Cloud microphysical and radiative properties for parameterization and satellite monitoring of the indirect effect of aerosol on climate, J. Geophys. Res, 108(D15), 8632, doi:10.1029/2002JD002682, 2003.

Burnet, F. and Brenguier, J.-L.: Observational study of the entrainment-mixing process in warm convective clouds, J. Atmos. Sci., 64, 1995-2011, 2007.

Chang, F.-L. and Li, Z.: Estimating the vertical variation of cloud droplet effective radius using multispectral nearinfrared satellite measurements, J. Geophys. Res., 107(D15), doi:10.1029/2001JD000766, 2002.

Chen, R., Wood, R., Li, Z., Ferraro, R., and Chang, F.-L.: Studying the vertical variation of cloud droplet effective radius using ship and space-borne remote sensing data, J. Geophys. Res., 113, D00A02, doi:10.1029/2007JD009596, 2008.

Feingold, G.: Modeling of the first indirect effect: Analysis of measurement requirements, Geophys. Res. Lett., 30, 1997, doi:10.1029/2003GL017967, 2003.

Feingold, G., Remer, L. A., Ramaprasad, J., and Kaufman, Y. J.: Analysis of smoke impact on clouds in Brazilian biomass burning regions: An extension of Twomey's approach, J. Geophys. Res., 106(D19), 22907-22922, 2001.

Feingold, G., Eberhard, W. L., Veron, D. E., and Previdi, M.: First measurements of the Twomey indirect effect using ground-based remote sensors, Geophys. Res. Lett., 30, 1287, doi:10.1029/2002GL016633, 2003.

French, J. R., Vali, G., and Kelly, R. D.: Evolution of small cumulus clouds in Florida: Observations of pulsating growth, Atmos. Res., 52, 143-165, 1999.

Freud, E., Rosenfeld, D., Andreae, M. O., Costa, A. A., and Artaxo, P.: Robust relations between $\mathrm{CCN}$ and the vertical evolution of cloud drop size distribution in deep convective clouds, Atmos. Chem. Phys., 8, 1661-1675, doi:10.5194/acp-8-1661-2008, 2008.

Frisch, A. S., Fairall, C. W., and Snider, J. B.: Measurement of stratus cloud and drizzle parameters in ASTEX with a Ka-band Doppler radar and a microwave radiometer, J. Atmos. Sci., 52, 2788-2799, 1995.

Heus, T., Jonker, H. J. J., Van den Akker, H. E. A., Griffith, E. J., Koutek, M., and Post, F. H.: A statistical approach to the life cycle analysis of cumulus clouds selected in a virtual reality environment, J. Geophys. Res., 114, D06208, doi:10.1029/2008JD010917, 2009.

Hill, A. A., Feingold, G., and Jiang, H.: The influence of entrain- ment and mixing assumption on aerosol-cloud interactions in marine stratocumulus, J. Atmos. Sci., 66, 1450-1464, 2008.

Hudson, J. G. and Yum, S. S.: Maritime-continental drizzle contrasts in small cumuli, J. Atmos. Sci., 58, 915-926, 2001.

Jeffery, C. A. and Reisner, J. M.: A study of cloud mixing and evolution using PDF methods. Part one: cloud front propagation and evaporation, J. Atmos. Sci., 63, 2848-2864, 2006.

Jiang, H., Feingold, G., Jonsson, H. H., Lu, M.-L., Chuang, P. Y., Flagan, R. C., and Seinfeld, J. H.: Statistical comparison of properties of simulated and observed cumulus cloud in the vicinity of Houston during the Gulf of Mexico Atmospheric Composition and Climate Study (GoMACCS), J. Geophys. Res., 113, D13205, doi:10.1029/2007JD009304, 2008.

Lehmann, K., Seibert, H., and Shaw, R. A.: Homogeneous and inhomogeneous mixing in cumulus clouds: dependence on local turbulence structure, J. Atmos. Sci., 66, 3641-3659, 2009.

Lensky, I. M. and Rosenfeld, D.: Satellite-based insights into precipitation formation processes in continental and maritime convective clouds at nighttime, J. Appl. Meteorol., 42, 1227-1233, 2003.

Lensky, I. M. and Rosenfeld, D.: The time-space exchangeability of satellite retrieved relations between cloud top temperature and particle effective radius, Atmos. Chem. Phys., 6, 2887-2894, doi:10.5194/acp-6-2887-2006, 2006.

Lohmann, U. and Feichter, J.: Global indirect aerosol effects: a review, Atmos. Chem. Phys., 5, 715-737, doi:10.5194/acp-5-7152005, 2005.

Lu, M.-L., Feingold, G., Jonsson, H. H., Chuang, P. Y., Gates, H., Flagan, R. C., and Seinfeld, J. H.: Aerosol-cloud relationships in continental shallow cumulus, J. Geophys. Res., 113, D15201, doi:10.1029/2007JD009354, 2008.

McComiskey, A. and Feingold, G.: Quantifying error in the radiative forcing of the first aerosol indirect effect, Geophys. Res. Lett., 35, L02810, doi:10.1029/2007GL032667, 2008.

McComiskey, A., Feingold, G., Frisch, A. S., Turner, D. D., Miller, M. A., Chiu, J. C., Min, Q., and Ogren, J. A.: An assessment of aerosol-cloud interactions in marine stratus clouds based on surface remote sensing, J. Geophys. Res., 114, D09203, doi:10.1029/2008JD011006, 2009.

Miles, N. L., Verlinde, J., and Clothiaux, E. E.: Cloud droplet size distributions in low-level stratiform clouds, J. Atmos. Sci., 57, 295-311, 2000.

Nakajima, T. and King, M. D.: Determination of the optical thickness and efffecitive particel radius of clouds from reflected solar radiation measurements, Part one: Theory, J. Atmos. Sci., 47, 878-1893, 1990.

Nakajima, T., Suzuki, Y. K., and Stephens, G. L.: Droplet growth in warm water clouds observed by the A-Train, Part 1: Sensitivity analysis of the MODIS-derived cloud droplet sizes, J. Atmos. Sci., 67, 1884-1896, 2010.

Platnick, S. and Twomey, S.: Determining the Susceptibility of Cloud Albedo to Changes in Droplet Concentration with the Advanced Very High-Resolution Radiometer, J. Appl. Meteorol., 33, 334-347, 1974.

Pawlowska, H., Grabowski, W. W., and Brenguier, J.-L.: Observations of the width of cloud droplet spectra in stratocumulus, Geophys. Res. Lett., 33, L19810, doi:10.1029/2006GL026841, 2006.

Ricchiazzi, P., Yang, S., Gautier, C., and Sowle, D.: SBDART: A 
research and teaching software tool for plane-parallel radiative transfer in the Earth's atmosphere, Bull. Amer. Meteorol. Soc., 79, 2101-2114, 1998.

Rosenfeld, D. and Feingold, G.: Explanation of the discrepancies among satellite observations of the aerosol indirect effects, Geophys., Res., Lett., 30, 1776, doi:10/1029/2003GL017684, 2003.

Rosenfeld, D. and Lensky, I. M.: Satellite-based insights into precipitation formation processes in continental and maritime convective clouds, Bull. Am. Meteorol. Soc., 79, 2457-2476, 1998.

Schuller, L., Bennartz, R., Fischer, J., and Brenguier, J.-L.: An algrithm for the retrieval of droplet number concentration and geometrical thickness of statiform marine boundary clouds applied to MODIS radiometric observations, J. Appl. Meteo., 44, 28-44, 2005.

Small, J. D. and Chuang, P. Y.: New observations of precipitation initiation in warm cumulus clouds, J. Atmos. Sci., 65, 29722982, 2008.

Twohy, C. H., Petters, M. D., Snider, J. R., Stevens, B., Tahnk, W., Wetzel, M., Russell, L., and Burnet, F.: Evaluation of the aerosol indirect effect in marine stratocumulus clouds: Droplet number, size, liquid water path, and radiative impact, J. Geophys., Res., 110, D08203, doi:10.1029/2004JD005116, 2005.
Twomey, S.: Pollution and the planetary albedo, Atmos. Environ., 8, 1251-1256, 1974.

Twomey, S.: The influence of pollution on the shortwave albedo of clouds, J. Atmos. Sci., 34, 1149-1152, 1977.

Wang, M. and Penner, J. E.: Aerosol indirect forcing in a global model with particle nucleation, Atmos. Chem. Phys., 9, 239-260, doi:10.5194/acp-9-239-2009, 2009.

Warner, J.: The water content of cumuliform cloud, Tellus, 7, 449457, 1955.

Xue, H. and Feingold, G.: Large-eddy simulations of trade wind cumuli: Investigation of aerosol indirect effects, J. Atmos. Sci., 63, 1605-1622, 2006.

Zuidema, P., Xue, H., and Feingold, G.: Shortwave radiative impacts from aerosol effects on marine shallow cumuli, J. Atmos. Sci., 65, 1979-1990, 2008. 